\title{
Compressive strength characteristics of kenaf fibre reinforced cement mortar
}

\author{
Omoniyi Tope Moses, Duna Samson, Othman Musa Waila \\ Civil Engineering Department, Abubakar Tafawa Balewa University, PMB 0248, Bauchi, Bauchi State, Nigeria
}

\section{Email address:}

tpmomoniyi@gmail.com (O. T. Moses), dunamine@yahoo.com (D. Samson)

\section{To cite this article:}

Omoniyi Tope Moses, Duna Samson, Othman Musa Waila. Compressive Strength Characteristics of Kenaf Fibre Reinforced Cement Mortar. Advances in Materials. Vol. 4, No. 1, 2015, pp. 6-10. doi: 10.11648/j.am.20150401.12

\begin{abstract}
This paper presents the findings of an investigation on the compressive strength properties of kenaf fiber composite mortar. Water-retted kenaf fibers were used as reinforcement in cement mortar. Fiber contents of $1 \%, 2 \%$ and $3 \%$ (by weight of cement) with varying lengths of $10 \mathrm{~mm}, 20 \mathrm{~mm}$ and $30 \mathrm{~mm}$ were used to produce $50 \mathrm{~mm}$ mortar cubes. The Composite mortars were cured in water for $3,7,14,21$, and 28days. A total of 150 mortar cubes were used for the study. Density, water absorption and compressive strength tests were conducted on the composite mortar. Regression analysis was carried out on the compressive strength results using Minitab 15. The results showed that water absorption and density of the composite mortar increased as the volume of fiber and length increased. Compressive strength decreased with increasing fiber volume and length. However, there was increase in compressive strength of between $0.21 \%-22.3 \%$ for composite mortar containing $1-3 \%$ volume of fiber with $10 \mathrm{~mm}$ fiber length. The fitted regression model showed a perfect relationship $\left(\mathrm{R}^{2}=84.5 \%\right)$ between compressive strength, fiber volume, fiber length and curing age. Therefore, fiber volume, fiber length and curing are useful predictors of the selected model. Model adequacy test reveals that the fitted regression model is highly adequate. There was no statistically significant difference in the compressive strength of the control samples and those containing 1-3\% fiber volumes with fiber length of $10 \mathrm{~mm}$.
\end{abstract}

Keywords: Cement, Compressive Strength, Kenaf Fiber, Reinforcement, Mortar, Regression, ANOVA

\section{Introduction}

In times past, reinforcing steel, plastic and glass fibers were often used as reinforcement for cement mortar and concrete. However, these reinforcements are synthetic materials and expensive [1]. In recent times, a good number of natural fibers such as, coconut fibers(coir), Sugarcane bagasse fibers, bamboo fibers, have been used as natural reinforcement to improve the mechanical properties of mortar and concrete [2]-[4].

Kenaf fiber has been reported to possess excellent tensile and flexural strength when compared with other natural fibers [5]. Hanizam [6] and Ribot [7] reported a tensile strength of $930 \mathrm{MPa}$ and $500 \mathrm{MPa}$ respectively. This makes it an excellent natural fiber in improving the properties of concrete [8]

Many researchers have carried out investigations into the properties of concrete using kenaf fiber as reinforcement. Hanizam [9] investigated the mechanical properties of kenaf fiber foamed concrete. They included $0.25 \%$ and $0.40 \%$ kenaf fiber in foamed concrete and tested the composite concrete for compressive strength, flexural strength, and water absorption. Their results showed that kenaf fiber significantly improved the flexural strength. This increase reached $61 \%$ and $78 \%$ for $0.25 \%$ and $0.4 \%$ kenaf fiber inclusion respectively. There was also increase in water of $7 \%$ and $9 \%$ respectively for the same kenaf fiber concrete. However, there was slight decrease in compressive strength with inclusion of kenaf fiber. Bhutta [10] used kenaf fiber to strengthen reinforced concrete beams. Their results reveal that kenaf fiber increased the ultimate tensile strength of the composite beams. Arumala [11] grinded kenaf fiber and mixed it with magnesium oxychloride cement and water to produce building blocks. Their findings reveal that the blocks gained compressive strength steadily, attaining about $50 \%$ of the target strength in 15 days. They concluded that the blocks would be cost effective in the construction of one storey building. Udoeyo et al [12] used kenaf fiber as reinforcement in mortar composites of size $650 \mathrm{~mm} \times 450 \mathrm{mmx} 8 \mathrm{~mm}$. They used three fiber contents of $0.5 \%, 1.0 \%$ and $1.5 \%$ at four (4) 
different fiber lengths of $20 \mathrm{~mm}, 30 \mathrm{~mm}, 40 \mathrm{~mm}$ and $50 \mathrm{~mm}$. Their results showed that flexural toughness and impact resistance was enhanced with addition of kenaf fiber. Although, incorporation of kenaf fiber increased water absorption of the composite mortar, all the values fell within the acceptable limit of 16\% specified by ASTM C221-77.

This study focuses on the compressive strength of kenaf fiber reinforced cement mortar. Mathematical models relating compressive strength, fiber volume and length were proposed and examined.

\section{Materials}

\subsection{Materials}

The kenaf fibers used for this work were obtained from a farm in Bauchi state, north eastern Nigeria. Water- retting was carried out on the collected kenaf fiber for four (4) weeks, after which the fibers were washed and dried. The dried fibers were chopped into different lengths of $10 \mathrm{~mm}, 20 \mathrm{~mm}$ and $30 \mathrm{~mm}$.Ashaka brand of Ordinary Portland Cement (OPC) was used throughout the research work. It conforms to BS 12:1978 and the Nigerian Industrial Standard (NIS) 444-1:2003 Specification. The chemical and physical properties of Ashaka cement are presented in Table 1 and 2 respectively. Fine aggregate used was river sand obtained from a stream just outside Bauchi town. The sieve analysis results presented in Table 3 shows that it falls within zone 2. Portable drinking water was used for the production of mortar and as such no test was performed on it.

Table 1. Chemical Properties of Ashaka Cement.

\begin{tabular}{lcc}
\hline Oxide & Weight (\%) & limits specified by BS12 (1989) \\
\hline $\mathrm{S}_{\mathrm{i}} \mathrm{O}_{2}$ & 19.68 & $17-25$ \\
$\mathrm{Fe}_{2} \mathrm{O}_{3}$ & 6.44 & $3-8$ \\
$\mathrm{Al}_{2} \mathrm{O}_{3}$ & 3.32 & $0.5-6.0$ \\
$\mathrm{CaO}$ & 60.92 & $60-67$ \\
$\mathrm{MgO}$ & 0.97 & $0.1-4.0$ \\
$\mathrm{SO}_{3}$ & 2.28 & $1-3$ \\
$\mathrm{Na}_{2} \mathrm{O}$ & 0.12 & - \\
$\mathrm{K}_{2} \mathrm{O}$ & 0.85 & - \\
\hline
\end{tabular}

Table 2. Physical Properties of Ashaka Cement.

\begin{tabular}{lcc}
\hline Oxide & Weight (\%) & limits specified by BS12 (1989) \\
\hline Specific Gravity & 3.15 & - \\
Fineness $\left(\mathrm{m}^{2} / \mathrm{kg}\right)$ & 370 & 275 \\
Loss on ignition & 1.0 & 1.2 \\
Soundness $(\mathrm{mm})$ & 2 & 10 \\
\hline
\end{tabular}

Table 3. Sieve Analysis of fine aggregate.

\begin{tabular}{lcc}
\hline Oxide & Percentage passing (\%) & limits specified by BS882 (1973) \\
\hline $10 \mathrm{~mm}$ & 100 & 100 \\
$5 \mathrm{~mm}$ & 98.2 & $89-100$ \\
$2.36 \mathrm{~mm}$ & 83.62 & $60-100$ \\
$1.18 \mathrm{~mm}$ & 63.77 & $30-100$ \\
$600 \mu \mathrm{m}$ & 43.77 & $15-100$ \\
$300 \mu \mathrm{m}$ & 20.42 & $5-70$ \\
$150 \mu \mathrm{m}$ & 2.50 & $0-15$ \\
$75 \mu \mathrm{m}$ & 0.54 & - \\
Pan & 0.00 & - \\
\hline
\end{tabular}

\subsection{Methods}

\subsubsection{Mortar Production}

A mortar mix of 1: 2.6(cement : sand) was used with a cement content of $210 \mathrm{~kg} / \mathrm{m}^{3}$, fine aggregate, $554 \mathrm{~kg} / \mathrm{m}^{3}$ and a water-cement ratio of approximately 0.55 . Batching was done by means of the weighing balance. The weighed sand and cement were mixed thoroughly until a homogeneous mixture was obtained. The required quantity of fiber was added and mixed carefully to ensure uniformity after which water was added. $50 \mathrm{~mm}$ cubes were cast from each mix in accordance with BS 1881: Part 1 specification. The hardened mortar samples were demoulded after 24hours and completely immersed in a curing tank. A total of 150 mortar cubes were produced for the study.

\subsubsection{Water Absorption Test}

Water absorption test was conducted on the different composite mortar after 28days. The test was conducted in accordance in accordance with BS 1881 Part 122:1982.

\subsubsection{Density Test}

Density of the composite mortar was determined in accordance with BS 1881: Part 107:1983 specification. The test was conducted on the compressive strength specimens before they were crushed to failure.

\subsubsection{Compressive Strength Test}

Compressive strength test was conducted on the kenaf fiber reinforced cement mortar. The test was conducted in accordance with ASTM C109-1990.Three cubes were cast for each fiber volume and length. They were crushed at the end of each curing period using the compressive strength test digital machine (TQ SM 100) and the average crushing strength recorded. A total of 150 mortar cubes were produced for the study.

\section{Results and Discussion}

\subsection{Water Absorption and Density of the Composite Mortar}

Table 4. Densities and Water absorption of the composite Mortar.

\begin{tabular}{|c|c|c|c|c|}
\hline $\begin{array}{l}\text { Mix } \\
\text { ID }\end{array}$ & $\begin{array}{l}\text { Fiber } \\
\text { Volume(\%) }\end{array}$ & $\begin{array}{l}\text { Fiber } \\
\text { Length }(\mathrm{mm})\end{array}$ & $\operatorname{Density}\left(\mathrm{kg} / \mathrm{m}^{3}\right)$ & $\begin{array}{l}\text { Water } \\
\text { Absorption } \\
(\%)\end{array}$ \\
\hline KF0 & 0 & 0 & 2400 & 3.27 \\
\hline KF1 & 1.0 & 10 & 2408 & 3.23 \\
\hline KF2 & 2.0 & 10 & 2424 & 3.19 \\
\hline KF3 & 3.0 & 10 & 2512 & 3.31 \\
\hline KF4 & 1.0 & 20 & 2520 & 3.51 \\
\hline KF5 & 2.0 & 20 & 2556 & 3.41 \\
\hline KF6 & 3.0 & 20 & 2560 & 3.56 \\
\hline KF7 & 1.0 & 30 & 2392 & 3.48 \\
\hline KF8 & 2.0 & 30 & 2344 & 4.20 \\
\hline KF9 & 3.0 & 30 & 2328 & 4.42 \\
\hline
\end{tabular}

The water absorption and densities of the composite mortar is presented in Table 4. The water absorption values of all the composite mortar is seen to be slightly more than that of the control sample except for mortar containing $10 \mathrm{~mm}$ fiber 
length at $1 \%$ and $2 \%$ fiber volume. Similar findings had been reported by Udoeyo et al [13]. The increased water absorption may be attributed to the increase in void and pore with the inclusion of kenaf fiber in the cement mortar However, all the water absorption values fall within the $16 \%$ acceptable limit specified by ASTM C 211-77. This implies that kenaf fiber length of $10 \mathrm{~mm}$ and no more than $2 \%$ fiber volume can be used to reduce the water absorption of mortar and consequently improve its durability.

The densities of the composite mortar were observed to be slightly greater than that of the plain mortar. This may be attributed to the increased in weight of the composite mortar through the inclusion of kenaf fiber.

\subsection{Compressive Strength of Composite Mortar}

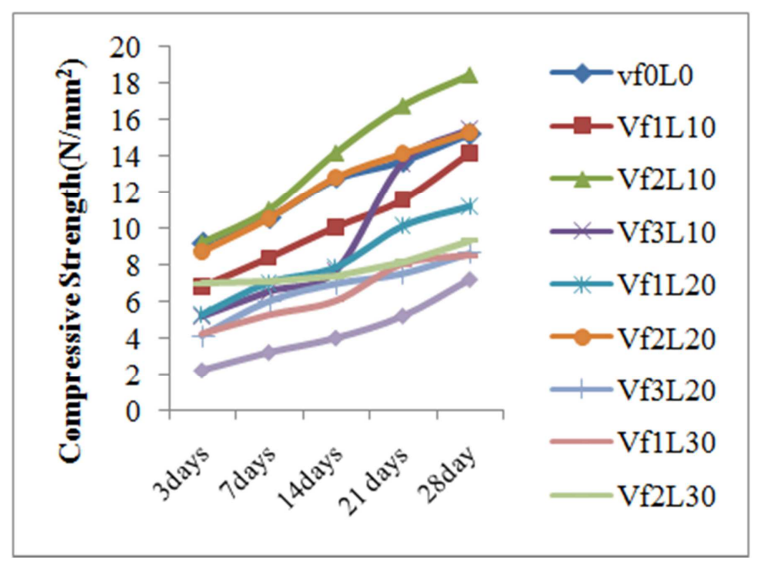

Figure 1. Plot of Compressive strength versus Curing age.

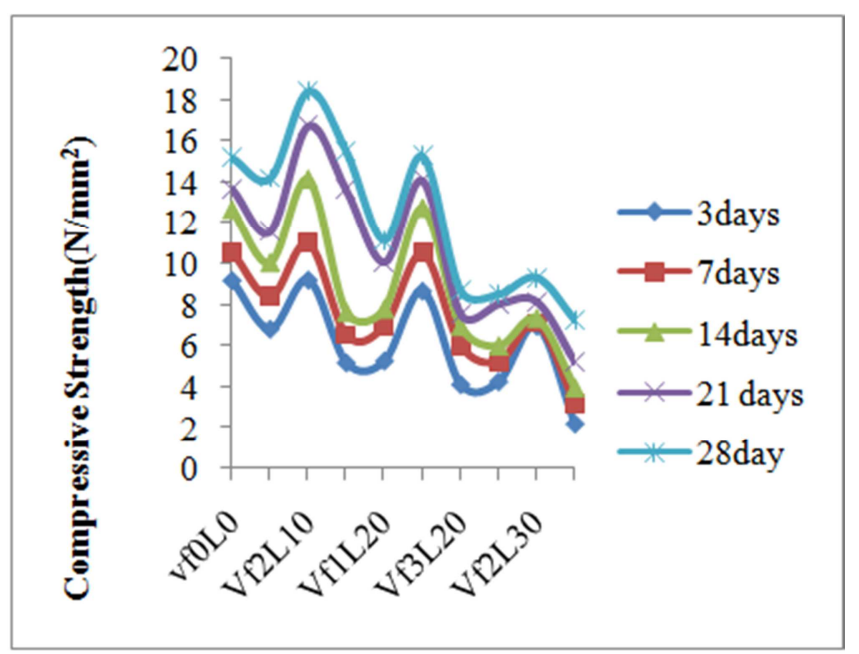

Figure 2. Plot of Compressive strength versus fiber volume and fiber length.

The compressive strength test results are presented in Table 4. Figure 1 and 2 shows the variation of compressive strength with fiber length $\left(f_{1}\right)$, fiber volume $\left(v_{f}\right)$ and curing age $\left(C_{a}\right)$. It can be seen that the compressive strength of the composite mortar containing $\mathrm{V}_{\mathrm{f}}$ of $2 \%, \mathrm{~L}_{\mathrm{f}}=10 \mathrm{~mm}$, and $\mathrm{V}_{\mathrm{f}}$ of $2 \%$, $\mathrm{L}_{\mathrm{f}}=10 \mathrm{~mm}$ showed improvement when compared with the control samples. For instance, for the mix designated $\mathrm{V}_{\mathrm{f}} 2 \mathrm{~L}_{\mathrm{f}} 10$, the compressive strength of this mortar increased by $0.21 \%$, $4.2 \%, 11.7 \%, 22.3 \%$ and $21.3 \%$ of the control samples at the end of 3,7,14,21 and 28 days of curing. This behavior may be due to the presence of lignin in the kenaf fiber used in the production of composite mortar. It has been reported that lignin can improve the compressive strength of cement paste [14]. Compressive strength was also seen to increase with curing age irrespective of the volume of fiber or fiber length.

Table 5. Compressive strength of composite Mortar.

\begin{tabular}{|c|c|c|c|c|c|c|c|}
\hline \multirow{2}{*}{$\begin{array}{l}\text { Mix } \\
\text { ID }\end{array}$} & \multirow{2}{*}{$V_{f}(\%)$} & \multirow{2}{*}{$\mathbf{L}_{\mathbf{f}}(\mathbf{m m})$} & \multicolumn{5}{|c|}{ Compressive Strength(N/mm $\left.\mathrm{m}^{2}\right)$} \\
\hline & & & 3days & 7days & 14days & 21days & 28days \\
\hline KF0 & 0 & 0 & 9.20 & 10.6 & 12.7 & 13.7 & 15.20 \\
\hline KF1 & 1 & 10 & 6.82 & 8.40 & 10.10 & 11.6 & 14.20 \\
\hline KF2 & 2 & 10 & 9.22 & 11.04 & 14.18 & 16.76 & 18.44 \\
\hline KF3 & 3 & 10 & 5.18 & 6.54 & 7.68 & 13.62 & 15.50 \\
\hline KF4 & 1 & 20 & 5.27 & 7.01 & 7.85 & 10.09 & 11.17 \\
\hline KF5 & 2 & 20 & 8.68 & 10.52 & 12.78 & 14.10 & 15.28 \\
\hline KF6 & 3 & 20 & 4.12 & 6.02 & 6.99 & 7.55 & 8.67 \\
\hline KF7 & 1 & 30 & 4.26 & 5.28 & 6.04 & 8.04 & 8.50 \\
\hline KF8 & 2 & 30 & 6.98 & 7.12 & 7.38 & 8.16 & 9.32 \\
\hline KF9 & 3 & 30 & 2.20 & 3.20 & 4.00 & 5.22 & 7.24 \\
\hline
\end{tabular}

\section{Statistical Analysis}

Regression model was fit using the compressive strength data. The compressive strength, $\mathrm{f}_{\mathrm{c}}$ was taken as the dependent variable while the fiber length, $\mathrm{f}_{\mathrm{l}}$, fiber volume $\left(\mathrm{v}_{\mathrm{f}}\right)$ and curing age $C_{a}$ were taken as the in dependent variable. The result is presented in Table 6 . The regression equation is given by:

$$
f_{c}=7.83+6.79 v_{f}-0.389 l_{f}+0.243 c_{a}-2.21 v_{f}^{2}+0.0523 v_{l} l_{f}
$$

The coefficient of variation of the fitted model(R-Squared) gave a value of $84.5 \%$. This value is expected to be as high as possible to prove the relationship or connections between two or more variables in a model. Coefficient of variation of $84.5 \%$ implies that $84.5 \%$ of variation in the compressive strength is explained by the regression model with fiber length, fiber volume and curing age as variables. This shows a perfect correlation and the generated model is highly significant. The $\mathrm{P}$-values in Table 6 is a measure of the likelihood that the true coefficient is zero. If the $\mathrm{P}$-value of any independent variable is less than the selected level of significance (i.e. $5 \%$ level of significance, $\mathrm{P} \leq 0.05)$, then the variable in question is not significant. It can be deduced that all the variables are significant except the interaction variable $\left(\mathrm{V}_{\mathrm{f}} \mathrm{L}_{\mathrm{f}}\right)$. Figure 3 and 4 shows the model adequacy test plots. The constant variance assumption was checked with residual versus fits plots shown in Figure 3. The plot showed a random distribution of the residuals on both sides of the zero error line. As it can be seen, the residuals(noise) have non-recognizable pattern. (i.e. the variance is constant), there were no unusual observations which further confirms the adequacy of the proposed model[15]. The population normality was checked with the normal probability plot as shown in Figure 4. It can be clearly seen that the residuals aligns themselves closely and tends to resemble a straight line with not so much variation[16].The compressive strength test results of the composite mortar were subjected to a one way ANOVA at 5\% level of significance. The computations are presented in Table 8. There was no 
significant difference between means of the compressive strength of the control mortar and those of the mixes designated KF1, KF2, KF3 and KF5 (P $\leq 0.05)$. Therefore, mortar containing not more than $1-3 \%$ with fiber length of $10 \mathrm{~mm}$ only can be used where strength is the criterion.

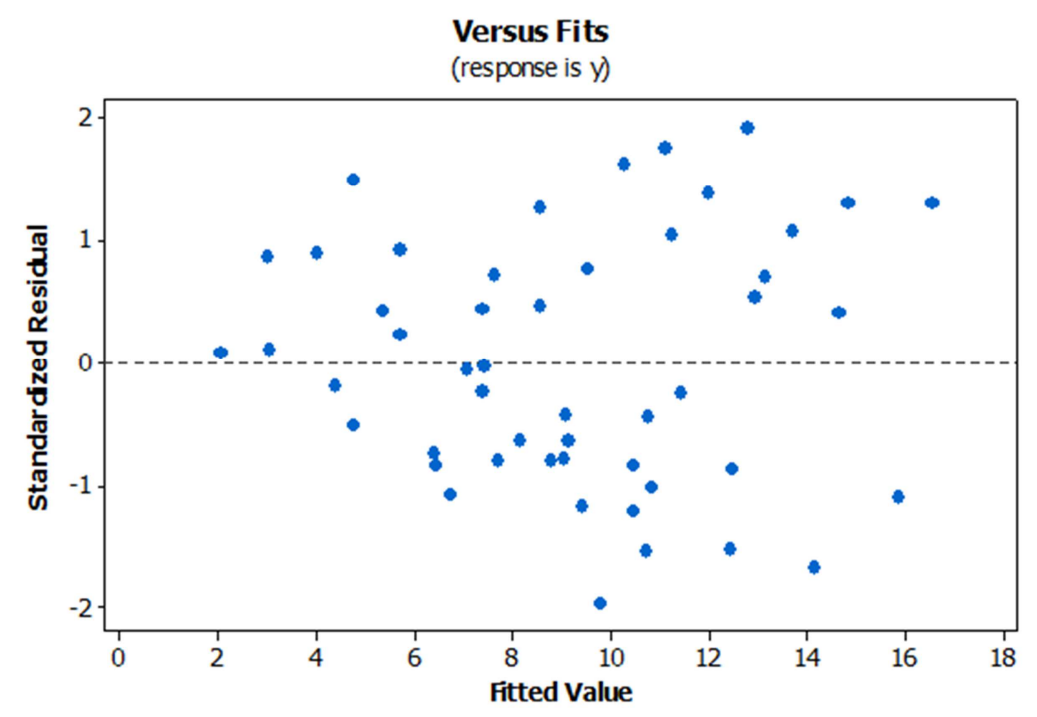

Figure 3. Residual versus fitted value plot for compressive strength.

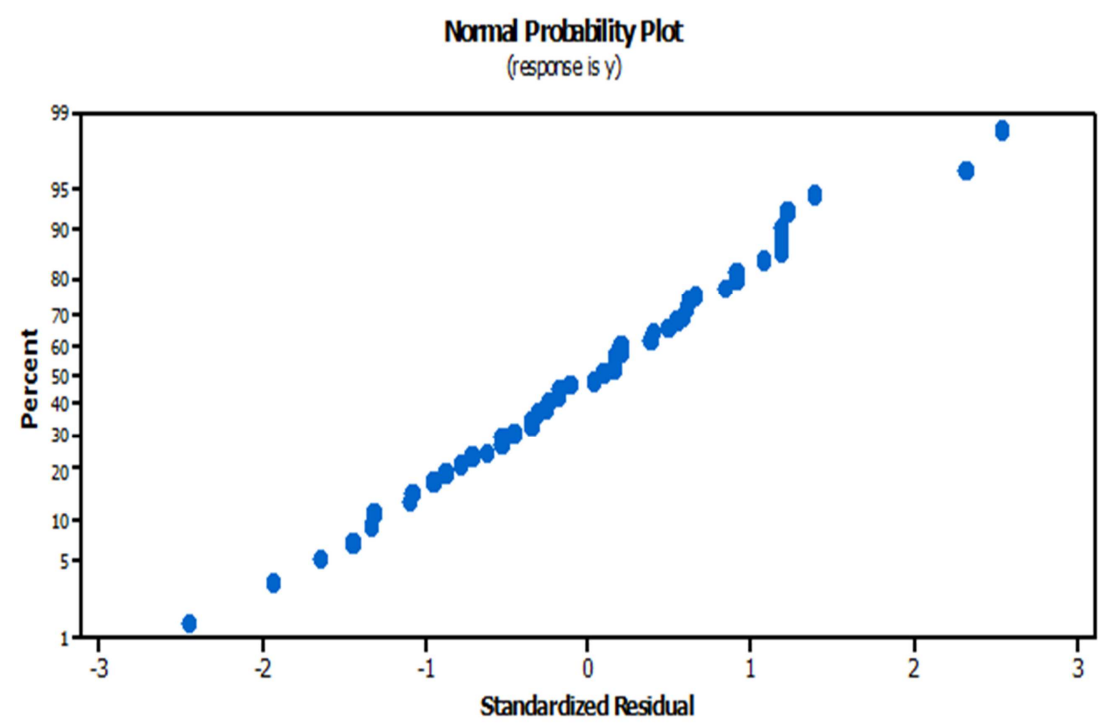

Figure 4. Normality Probability Plot.

Table 6. Regression analysis on Compressive strength tests results.

\begin{tabular}{llllll}
\hline Predictors & Coeff & SE Coeff & T & P & Significance \\
\hline Constant & 7.83 & 0.765 & 10.23 & 0.00 & Yes \\
$\mathrm{V}_{\mathrm{f}}$ & 7.79 & 1.09 & 6.19 & 0.00 & Yes \\
$\mathrm{L}_{\mathrm{f}}$ & -0.38 & 0.059 & -6.53 & 0.00 & Yes \\
$\mathrm{C}_{\mathrm{a}}$ & 0.243 & 0.025 & 9.90 & 0.00 & Yes \\
$\mathrm{V}_{\mathrm{f}}^{2}$ & -2.20 & 0.365 & -6.04 & 0.00 & Yes \\
$\mathrm{V}_{\mathrm{f}} \mathrm{L}_{\mathrm{f}}$ & 0.052 & 0.028 & 1.82 & 0.076 & No \\
\hline
\end{tabular}

Table 7. ANOVA for Compressive strength test results.

\begin{tabular}{llllll}
\hline Source & DF & SS & MS & F & P \\
\hline Regression & 5 & 597.62 & 119.52 & & \\
Error & 44 & 109.53 & 2.49 & 48.01 & 0.00 \\
Total & 49 & 707.15 & & & \\
\hline
\end{tabular}

Table 8. One way ANOVA for Strength at 5\% level of Significance.

\begin{tabular}{lcccc}
\hline Mix ID & Mean Strength & Variance & P & Remarks \\
\hline KF0 & 12.28 & 5.76 & - & - \\
KF1 & 10.22 & 8.16 & 0.253 & N.S \\
KF2 & 13.93 & 14.74 & 0.440 & N.S \\
KF3 & 9.70 & 20.88 & 0.297 & N.S \\
KF4 & 8.28 & 5.62 & $0.029 *$ & SS \\
KF5 & 12.27 & 7.15 & 0.996 & N.S \\
KF6 & 6.67 & 2.95 & $0.0028^{*}$ & SS \\
KF7 & 6.42 & 3.27 & $0.0024^{*}$ & SS \\
KF8 & 7.79 & 0.94 & $0.0047^{*}$ & SS \\
KF9 & 4.37 & 3.79 & $0.0000^{*}$ & SS \\
\hline
\end{tabular}

*NS means not significant, *SS means significant difference. 


\section{Conclusions}

Based on the outcome of this work, the following conclusion can be made:

1) The addition of kenaf fiber generally increased the water absorption of the composite mortar.

2) $1 \%$ and $2 \%$ fiber addition with $10 \mathrm{~mm}$ length reduced the water absorption of the composite mortar by up to $2.44 \%$.

3) The densities of the composite mortar increased with increasing fiber length and volume.

4) Compressive strengths of the composite mortar increased at $2 \%$ fiber volume with 10 and $20 \mathrm{~mm}$ lengths and decreased for other mixes at all curing ages.

5) Maximum strength increase was observed at 2\% fiber volume and $10 \mathrm{~mm}$ fiber length. This value reached $22.3 \%$ of the strength of the control mortar.

6) There is no statistically significant difference in the compressive strength of mortar containing 1-3\% fiber volume with $10 \mathrm{~mm}$ length against those used as control samples.

7) From this study, 1- 3\% fiber volume with $10 \mathrm{~mm}$ length can be used to improve the compressive strength of mortar.

8) Fitted regression model on the compressive strength is highly significant.

9) Due to the high coefficient of variation $\left(R^{2}=84.5 \%\right)$, fiber volume, fiber length and curing age are significant predictors of the regression model.

\section{References}

[1] Paul, A.C, John, J.B and Steven, J.F(1999). Agricultural waste materials for composites: A Canadian reality. Paper Presented at Center for Management Technology, Global Panel Based Conference, Nikko Hotel, Kuala Lumpur, 18-19 October, 1999.

[2] Othman, M.W (2011). The Effects of Kenaf Fiber on the strength of cement Mortar .Unpublished B.Eng Thesis, Civil Engineering Department Abubakar Tafawa Balewa University, Bauchi.

[3] Kurtis, K.E. (2007)..CEE 8813 Natural Fiber Reinforced concrete, $<$ http://www.ce.gatech.edu/\%/ natfiber.pdf.html >, accessed November 2014.

[4] Ghazali, M.J, Azhari, C.H, Abdullah, S and Omar, M,Z(2008). Characterization of Natural Fibers(Sugarcane Bagasse) in cement Composites. Proceedings of the world congress on Engineering, July 2-4, London U.K
[5] Prakash, T(2009). Processing and Characterization Of Natural Fiber Reinforced Polymer Composites. Unpublished B.Tech Thesis, Mechanical Engineering Department, National Institute of Technology Rourkela India.

[6] Hanizam,A,Maydin,A.O andAhmad,M.H (2013). "Mechanical and Durability properties of fiber lightweight foamed concrete". Australian Journal of Basic and Applied Sciences. 7(7), 14-21.

[7] N.M.H, Ribot, Z, Ahmad, and N.K Mustaffa(2011) "Mechanical Properties of Kenaf Fiber Composite using Co-cured In-Line Fiber Joint," International Journal of Engineering Science and Technology. 8,(3), 269-272.

[8] I.S. Aji, S.M. Sapuan1, E.S. Zainudin and K. Abdan(2009), "Kenaf fibers as reinforcement for polymeric composites: a review," International Journal of Mechanical and Materials Engineering,4(3), No. 3, 239-248.

[9] Hanizam,A,Maydin,A.OandAhmad,M.H (2013). "Mechanical and Durability properties of fiber lightweight foamed concrete". Australian Journal of Basic and Applied Sciences. 7(7), 14-21.

[10] Bhutta,M.A. NurHafizah, A.K, Jamaludin, M.Y, Warid,M.HIsmail,M and Azman, M(2009)."Strengthening reinforced concrete beams using kenaf fiber reinforced polymer composites laminates".Proceedings of the international conference on sustainable construction materials and technologies.

[11] Arumala,J(2014). “Kenaf building Blocks". Proceedings $121^{\text {st }}$ ASEE Annual Conference and Exposition, June 15-18, Indianapolis.

[12] F.F Udoeyo and A ,Adetifa(2012) " Characteristics of Kenaf Fiber-Reinforced Mortar Composite," International Journal of Reviews and Engineering Research.12,(1), 18-26.

[13] F.F Udoeyo and A ,Adetifa(2012) " Characteristics of Kenaf Fiber-Reinforced Mortar Composite," International Journal of Reviews and Engineering Research.12,(1), 18-26.

[14] Akriti, A ,Nirmala K and Soumitra B(2014). Derivatives and Applications of Lignin - An Insight. The SciTech Journal. 1(7), 30-36

[15] Multiple Regression and Model Checking (2011). Tutorial, Department of Mathematics and Statistic, University of Reading. pp 1-6.

[16] John Pan (2011). Minitab Tutorial and Design of Experiment. pp1-32 